\title{
ПРОЦЕСС СОЗДАНИЯ АЛЬТОВЫХ ТРАНСКРИПЦИЙ: ОТ ТЕОРИИ \\ К ПРАКТИКЕ
}

CSCSTI 18.41.51

UDC 787.2:78.083.82

DOI 10.47940/cajas.v6i4.488

\author{
Гульнар Абдирахман ${ }^{1}$, \\ Айжан Бекенова ${ }^{1}$ \\ ${ }^{1}$ Қазахская национальная консерватория \\ имени Курмангазы (Алматы, Қазахстан)
}

Аннотация. Статья посвящена определению основных этапов процесса создания транскрипций для альта. Актуальность темы определяется необходимостью пополнения концертнопедагогического репертуара для альта, обусловившей востребованность практики транскрибирования как исполнителями на альте, так и педагогами. На данный момент работы, раскрывающие специфику этого процесса и присущие ему закономерности, фактически отсутствуют.

Методология изучения базируется на общенаучных методах - анализе, синтезе, а также исходит из методологической установки Бориса Бородина, согласно которой транскрипция выступает «зафиксированной интерпретацией художественных ценностей». Сам процесс создания транскрипции представлен как акт перевода исполнительского видения произведения в его текстовую форму.

По итогам исследования определены основные этапы создания транскрипций, внутреннее содержание которых определяется статусом творца и его внешней мотивацией. Первый, этап подбора произведения, реализует целевые установки автора, побудившие его обратиться к созданию новой версии произведения, и определяет принципы работы с оригинальным текстом. От того, какую цель преследует автор, зависит сущность основного этапа процесса транскрибирования: цель определяет выбор метода работы с первоисточником. Основной этап работы над транскрипцией имеет практико-ориентированный характер, его цель графическая фиксация новой версии произведения. Процесс создания транскрипции в условиях "зафиксированной интерпретации" сопровождается озвучиванием на инструменте возможных вариантов исполнительской трактовки каждого элемента музыкального текста. Третий этап апробация транскрипции, ее исполнение в целостном виде. Он дает возможность проверить удобство исполнения, убедительность звучания и необходимость внесения корректировок.

Статья содержит конкретные практические рекомендации авторам транскрипций, нацеленным на создание адаптированных для альта музыкальных произведений на основе переработки ранее созданных образцов.

Ключевые слова: альт, репертуар, транскрипция, обработка, интерпретация, производные жанры, уртекст.

Авторы заявляют об отсутствии конфликта интересов. Все авторы прочитали и одобрили окончательный вариант рукописи. 
Для цитирования: Абдирахман, Гульнар, и Айжан Бекенова. «Процесс создания альтовых транскрипций: от теории к практике». Central Asian Journal of Art Studies, т. 6, № 4, 2021, c. 55-69. DOI: 10.47940/cajas.v6i4.488.

\section{Введение}

$\mathrm{H}$ есмотря на то, что к настоящему времени круг оригинальных альтовых произведений значительно вырос, вопрос расширения репертуара для альта до сих пор не уходит с повестки дня. По сей день педагоги по классу альта, а также исполнители-практики обращаются к созданию альтовых транскрипций с целью введения в репертуар новых произведений. Это достаточно распространенная мировая практика, которая актуализирована не только в отношении альтового репертуара, но и музыки для других инструментов, на что указывают как отечественные, так и зарубежные исследователи (Howard-Jones 305 ).

Теоретическое изучение этапов создания альтовых транскрипций в музыкальной науке до сих пор не предпринималось, хотя широкая распространенность явления и его важная роль в формировании концертнопедагогического репертуара для альта определили частое упоминание о нем в научной литературе (Рогаль-Левицкий, 88; Стоклицкая, 12-13). В начале XXI столетия в зарубежном искусствознании появились научные труды, содержащие опыт изучения отдельных образцов альтовых транскрипций (Lee H., Van der Vyver E.), в том числе на примере творчества конкретных музыкантов (White Galvin R.). Среди русскоязычных музыковедческих работ аналогичной направленности следует назвать статью В. Климовой «Транскрипторская деятельность В. В. Борисовского (250-252). Акцентируя культивируемые музыкантом принципы отбора произведений для вторичной интерпретации, В. Қлимова намечает возможные пути изучения авторских альтовых транскрипций, которые взяты нами на вооружение при рассмотрении теории вопроса.

Широкая востребованность практики транскрибирования для альта актуализирует необходимость определения теоретических основ самого процесса, выявления присущих ему закономерностей и выработку конкретных рекомендаций по его осуществлению. Как справедливо отмечают исследователи, «теоретическое осмысление транскрипторской сферы... имеет практическую направленность современным транскрипторам, вероятно, будет небезынтересен обобщенный опыт мастеров прошлого (Бородин 9).

Но помимо «опыта мастеров прошлого», на сегодняшний день фактически не систематизированного и не обобщенного, важно понимание этапов этой работы, содержание каждого их них. Изучение в этом плане имеющейся альтовой транскрипторской литературы позволяет определить сложившиеся в этом виде деятельности подходы к решению практической задачи создания альтовой транскрипции, что представляется важным для ее развития и дальнейшего совершенствования.

Анализ имеющейся транскрипторской нотной литературы для альта показывает, что на данный момент работа казахстанской части ее создателей строится на обращении к положительному опыту российских, реже - европейских авторов. Подробнее этот ракурс был освещен в статье коллектива авторов «Creating Transcriptions and Adaptations for Viola in Kazakhstan: Retrospection, Theory and Practice» (Bekenova, et al. 1-14). 
Учитывая то, что отечественные авторы транскрипций работают, как правило, с национальным музыкальным материалом, инонациональный опыт интегрируется с практическими наработками, сложившимися на национальной почве, учитывающими специфические содержательные, тембровые и музыкально-языковые свойства казахской музыки. Цель данной статьи заключается в определении общих закономерностей процесса создания альтовых транскрипций, а также конкретизации особенных, национально характерных его черт, проявляющихся на уровне работы с музыкальным текстом первоисточника.

\section{Методы}

Преобладающая роль в создании транскрипторской нотной литературы для альта в Қазахстане принадлежит не композиторам, а исполнителям и педагогам-практикам. К ним относятся такие музыканты, как Е. Либерчук, Я. Фудиман, Н. Каримов, Д. Махмуд. Все они имеют одинаковый статус, позиционируя себя как сольные/ ансамблевые исполнители на альте и педагоги среднего и высшего музыкально-образовательного звеньев. Этот факт позволяет строить процесс изучения специфики их практической деятельности по созданию транскрипций в методологической опоре на теоретическую концепцию Б. Бородина, который на материале фортепианной музыки обозначил транскрипцию как «зафиксированную интерпретацию» (Бородин 3). Данное понятие, по нашему мнению, достаточно точно фиксирует суть процесса создания транскрипции музыкантом-исполнителем, который движется от «идеального», на его взгляд, варианта исполнения произведения к его нотной фиксации. Это позволяет применить данное определение и к условиям практики транскрибирования произведений для альта. Таким образом, сам процесс создания транскрипции предстает как акт перевода исполнительского видения произведения в его текстовую форму.

С другой стороны, немаловажен и тот факт, что представители казахстанской школы транскрибирования для альта это выходцы школы Я. Фудимана, для транскрипторской деятельности которого не свойственна свободная трактовка замысла и текста оригинала. Если часть транскрипторов, особенно в области фортепианной транскрипции, нацелена на показ своеобразия собственной интерпретации, индивидуальности прочтения авторского замысла, вплоть до преобразования художественного стиля произведения, то казахстанские исполнители-альтисты руководствуются, прежде всего, педагогическими задачами и потому являются сторонниками «охранительного подхода» к первоисточнику.

\section{Результаты}

Процесс создания транскрипции, как и любой другой творческий процесс, - это и технология, и ремесло, и возможность сделать новое художественное открытие. Транскрипция позволяет проявить индивидуальное видение, предложить в ходе его адаптации к новым инструментальным условиям иное прочтение первоисточника.

Уровень самостоятельности в прочтении авторского текста определяется как творческой одаренностью транскриптора, так и мотивационным аспектом, то есть теми задачами, которыми он руководствуется, приступая к обработке произведения. При этом, как показывает мировой опыт создания транскрипторских произведений для альта, установка на донесение идейно-художественного содержания произведения с учетом новых 
инструментальных условий является базовой, доминирующей.

Другой основополагающей установкой транскрипторской работы является достижение качества и полноценности звучания произведения. Для транскрипторов, в совершенстве владеющих инструментом, этот аспект закономерно является более легко достижимым и нередко продуцирует значительное обновление содержания произведения через усиление в нем концертных, виртуозных черт и свойств, позволяющих раскрыть высокий творческий потенциал творца-исполнителя. В этом видится диалектика процесса создания транскрипций как «зафиксированных интерпретаций», где в постоянном процессе взаимодействия находятся субъективные качества творца, мотивирующие его внешние обстоятельства, а также регулирующие «каноны» и «правила игры», присущие транскрипции как производному жанру.

Как показывает анализ изучаемой деятельности, процесс работы транскриптора в крупном плане представляет собой три основных этапа: подбор образца для транскрипции (предварительный этап), работа над переложением (основной этап), практическая апробация результатов (заключительный этап). В условиях, когда этим занимается исполнитель-практик, границы второго и третьего этапов нередко размываются: нотная фиксация происходит «по следам» проигрывания отдельных структурных элементов композиционного целого - мотивов, фраз, предложений, периодов, частей. Но и в таком случае этап апробации присутствует: под ним следует понимать публичное исполнение произведения как художественного целого, которое фиксирует его завершенность и самостоятельность. Рассмотрим содержание каждого этапа более детально.
Этап подбора произведения реализует, с одной стороны, целевые установки автора, побудившие его обратиться к созданию новой версии произведения, с другой - определяет закономерности и основополагающие принципы работы с оригинальным текстом. От того, какую цель преследует автор - создать образец для педагогического или концертного репертуара, «донести» без изменений смысловое содержание первоисточника или создать свое, оригинальное видение, зависит сущность основного этапа процесса транскрибирования: цель определяет выбор метода работы с первоисточником.

Предварительный этап нацелен также на выбор первоисточника, при этом, с учетом специфики звучания альта и его технических возможностей, этот выбор не безграничен. Тембр альта уникален, по характеристике Ю. Башмета он «гораздо глуше скрипки, звучание его направлено как бы внутрь себя, слабее резонирует, даже гнусавит. Но зато его звук - теплее, объемнее, а в смысле виртуозности альт почти так же совершенен, как скрипка» (6). Тембр альта характеризуют как «тембрхамелеон» из-за его «способности “сливаться” с другими тембрами, усиливая их драматургические и красочные функции» (Маршанский 165). Уникальность альтового тембра визитная карточка инструмента, но она же может выступать ограничивающим фактором при выборе образца для творческой переработки. Если же говорить о солирующих альтовых фрагментах, то следует также помнить о длине грифа инструмента, требующего от музыканта физической силы и ловкости для извлечения сильного и выразительного тона. Есть значительные различия в тембровых свойствах каждого звукового регистра и в их возможностях решать сложные технические задачи. Все это надо иметь в виду при выборе первоисточника. Если же задачи 
тембрового и технического соотнесения решены, то при транскрибировании произведений европейской классики нередко возникает дополнительный вопрос идентификации первоисточника с точки зрения приближенности к оригиналу. Отправной точкой для создания транскрипции может стать авторская рукопись, уртекст или интерпретирующая редакция произведения. Для принятия решения необходима большая самостоятельная исследовательская работа, в ходе которой имеющиеся варианты тщательно анализируются и выбирается тот единственный, переработка которого даст возможность в полной мере решить задачу предварительного этапа. Применительно к казахстанским произведениям такой вопрос ставится достаточно редко ввиду малочисленности произведений, имеющих несколько редакций. Как правило, редакции принадлежат самим композиторам и нацелены на улучшение исходной версии, поэтому последняя редакция может выступать в качестве своеобразного «эталона». Если же за основу берется образец казахской традиционной музыки и исходный материал представлен несколькими вариантами нотировок, то задача интерпретатора заключается в выборе наиболее «презентабельного» из них. Таковым может стать нотировка наиболее популярного, «узнаваемого» национальной аудиторией варианта народной/народно-профессиональной песни или кюя.

В национальном репертуаре очевидно предпочтение переработки образцов кобызовой музыки и произведений для кобыза с фортепиано. Это объясняется не только общей природой инструментов, как струнносмычковых, но и возможностью альта добиться максимального тембрового сходства с казахским народным инструментом. Из всех классических инструментов струнной группы именно альт наиболее близок в тембровом плане древнему кобызу. Его тембровые характеристики, как отмечает исследователь С. Мурзалиева, «находятся в строгом соответствии с его ритуально-магической функцией в культуре» (18-19). Опираясь на описания, оставленные очевидцами и исследователями шаманской практики, автор приводит такие характеристики звучания кобыза, как «таинственное», «гнусавое», «зловещее» (А. Затаевич), «резкое», «дикое» (А. Алекторов) (Мурзалиева 18-19). Эти характеристики вызывают прямые ассоциации с высказываниями выдающегося альтиста современности Ю. Башмета, который говорил, что «альт совершенно мистический, очень таинственный инструмент» (69).

При всей схожести альта со скрипкой, позволяющей, на первый взгляд, легко «перевести» ее репертуар в альтовый, последний имеет свои существенные «нюансы», без учета которых транскрипция не может получиться полноценной. Например, из-за разницы в размерах и большего расстояния пальцев левой руки приемы игры на альте отличаются от скрипичных приёмов. Они требуют другого способа звукоизвлечения и техники исполнения. Существенна в этом плане и тембровая разница: у альта он менее яркий, в нижнем регистре - более густой, глубокий, матовый, в верхнем - гнусавый, без яркого и блестящего звучания, присущего скрипке. Сочинения с широким диапазоном (в низком регистре - как на виолончели или в высоком - как на скрипке), с тонкой фактурой, на альте могут прозвучать невыразительно и даже плохо, так как разброс диапазона не позволит сохранить альтовый тембр. В то же время произведения, написанные для казахских народных инструментов, таких как кобыз, кыл-кобыз и даже домбра, могут 
выигрышно прозвучать в переложении для альта, так как их строй находится в общей регистровой зоне и примерных границах диапазона.

Учет разницы существенен

в отношении любого инструмента, с которого транскрибируется музыка для альта, поэтому предварительный этап работы предполагает обязательное углубление в технические особенности того инструмента, для которого создан оригинал, уточнение его специфических технических, регистровых, тембровоколористических характеристик, влияющих на создание художественного образа.

Необходимо уже на этом этапе выявить все сложности технического воплощения на альте тембровоколористической модели звучания и предварительно наметить существующие альтернативные решения. Очень важно тщательное изучение нотного текста оригинала с точки зрения правильного прочтения авторских ремарок и штриховых обозначений, уточнения диапазона и темпа применительно к каждому разделу формы и соотнесения их с возможностями альта. При решении создать максимально приближенную к оригиналу транскрипцию необходимо понять, каким образом добиться в новом инструментальном звучании сохранения содержательного и жанрово-стилевого своеобразия оригинала, общего колорита звучания и фактурного оформления. В этом плане большое значение имеет установка на воспроизведение отличительных свойств того «культурного кода», который несет сведения об исторической традиции, стиле эпохи, свойствах индивидуального почерка композитора. А это предполагает не только теоретическую подготовленность транскриптора, но и наличие у него солидного слухового музыкального багажа различной стилевой и жанровой направленности.

Установка на соответствие «культурному коду» произведения- оригинала обуславливает необходимость уже на предварительном этапе рассматривать оптимальные соотношения графического изображения нотного текста и его акустического аналога, тем более что «во множестве разнообразнейших композиторских обозначений, затрагивающих и регламентирующих едва ли не все стороны звукового воплощения музыкального произведения, ясно ощущается не их терминологическая основа, а скорее, символическая сущность, подразумевающая и требующая подчас различного толкования тех или иных атрибутов нотного текста» (Корноухов 82-83). Задача транскриптора - уловить эту «символическую сущность» и найти соответствующий способ ее преломления в обновленной версии нотного текста произведения. Это объясняет факт того, что транскрипторы стремятся к детализации своего нотного текста через ремарки, штриховые, темповые и динамические обозначения даже в том случае, когда их нет в тексте первоисточника.

В целом алгоритм действий транскриптора в этом отношении можно сформулировать как движение от привычного, «нормативного» прочтения нотного текста оригинала произведения через углубление в текст, распознавание и уточнение признаков авторской индивидуальности, «культурного кода» в его новом нотном и акустическом воплощении.

Основной этап работы над транскрипцией, как правило, не формализован строго в структурновременном плане, ибо «диалог» с композитором, национальной традицией здесь продолжается. Но он обретает более практикоориентированный характер, так как связан с непосредственной работой над транскрипцией. Цель этапа ее графическая фиксация. Процесс 
создания транскрипции в условиях «зафиксированной интерпретации» сопровождается, как правило, озвучиванием на инструменте возможных вариантов исполнительской трактовки каждого элемента музыкального текста.

Углубленный текстологический анализ первоисточника на этой стадии продолжается, но от общего ракурса его изучения внимание перемещается к деталям, частностям, позволяющим найти нужные приемы звукоизвлечения, штрихи, нюансы динамики и агогики, аппликатуру. Фактически транскриптор ищет на этом этапе пути воплощения в новую графическую форму музыкальных построений, наиболее оптимально звучащих на альте и максимально приближенных к оригиналу.

Технологическая сторона этого процесса достаточно трудоемка, она основывается на постоянном сравнении нотного текста и звучания транскрипции с аналогичными фрагментами оригинала. Как показывает практика, грамотно выполненная транскрипция напрямую зависит от знания оригинала. Здесь надо вновь обратить внимание на такие моменты, как сохранение в новых тембровых условиях стилевых и жанровых особенностей оригинала, специфики композиторского письма.

Безусловно, обстоятельства нового тембра, специфика звукоизвлечения на ином инструменте при максимальном приближении к звучанию оригинала повлекут за собой определенную трансформацию исполнительских приемов, штрихов, а иногда и нотного текста. Важным моментом при этом является соблюдение принципа «играбельности» и удобства исполнения. При этом следует иметь в виду, что параметр «удобства исполнения» имеет исторический характер. Альт со времени своего возникновения постоянно эволюционировал, и его нынешнее состояние - результат длительной исторической практики развития инструмента и игры на нем. Есть и субъективные критерии, зависящие от качества исполнителя: то, что удобно исполнять Л. Тертису, создававшему транскрипции «под себя», проблематично исполнить рядовому альтисту.

В условиях альта с его темброворегистровой неравномерностью звучания особенно важно достичь удобства исполнения мелодии. Эта задача может быть решена путем транспонирования текста музыкального произведения в удобную тональность, переноса октав, «облегчения» текстового перегруза или добавления двойных нот, аккордов. Важна также тщательная расстановка штрихов, фразировки, аппликатуры, агогики, динамических оттенков, включение смычковых приемов игры, адекватно отражающих характер произведения. При этом в приближенном к оригиналу транскрипторском тексте все изменения должны быть оправданны, поэтому новый нотный текст обычно снабжается подробными указаниями: обозначениями темпа, динамических оттенков, штрихов, аппликатуры, а также пояснениями относительно оригинала. Итогом основного этапа является готовый нотный текст, учитывающий все перечисленные выше факторы и содержащий необходимые указания и транскрипторские ремарки.

Этап апробации транскрипции, то есть ее исполнения в целостном виде, весьма важен для завершения процесса ее создания. Он дает возможность проверить удобство исполнения, убедительность звучания и необходимость внесения корректировок. В условиях приближенной к оригиналу транскрипции всегда происходит исполнительская адаптация к технической специфике нового инструмента при сохранении оригинальной идеи композитора. При этом текст не должен быть перегружен сложными техническими 
приемами, в особенности, если они отсутствовали в оригинале. На первом месте - выразительные свойства произведения, раскрытию которых не должны препятствовать неоправданные исполнительские сложности.

\section{Дискуссия}

Очевидно, что на практике при переработке первоисточника полученный результат может не всегда соответствовать специфике инструмента: транскрипция неудобна для исполнения, и это затрудняет донесение авторского замысла. Такие транскрипции, как правило, не задерживаются надолго в репертуаре исполнителей и педагогическом репертуаре. Этот же фактор, в принципе, объясняет то, что многие произведения музыкальной классики имеют несколько вариантов обработки, хотя мотивов для возвращения к одному и тому же образцу значительно больше: переработка может быть удобна в исполнительском плане, но не отражает в достаточной мере «культурный код» или авторскую индивидуальность, неточно выстроена в плане фразировки и артикуляции и т. д. Оригинальный авторский текст редко содержит подробные указания для исполнителя, и это дает транскриптору большой простор в выборе вариантов. Но если учитывать внетекстовый контекст оригинального произведения, закономерности исторического и авторского стиля, то круг транскрипторских средств значительно сужается. В этом отношении справедливо, на наш взгляд, высказывание исследователей В. Михно и Ю. Магомедовой, считающих, что «удобным нужно считать изложение, которое соответствует конструктивным особенностям инструмента, современному уровню техники и культуры исполнительства» (36).
Для уточнения своего видения первоисточника транскрипторы нередко специально создают аннотации для исполнителей, разъясняющие авторский подход к переработке. Например, голландский виолончелист Аннер Билсма, создавший редакции трех первых виолончельных сюит И. С. Баха, включил в свою работу аннотацию для современных исполнителей, где указал на необходимость принятия во внимание потенциала современных инструментов, претерпевших эволюцию со времен Баха, что фактически исключает полное достижение «баховского стандарта» в исполнении (Михно и Магомедова 33 ). Следует отметить, что это известное произведение классика барокко претерпело более 90 транскрипторских трансформаций для различных инструментов, и до сих пор вопрос его перевода в новые производные от уртекста образцы не исчерпан.

\section{Заключение}

Подводя итоги, отметим, что процесс создания транскрипций может быть структурирован в три основных этапа, границы которых, в силу творческого характера деятельности, достаточно условны. В целом этот процесс может быть уподоблен «герменевтическому кругу», предполагающему диалектику целого и частного: транскриптор движется от целостного представления оригинального произведения к осмыслению его деталей и затем вновь переходит в масштаб целого, сформированного в новом звуковом облике и качестве. Учитывая постоянную возвращаемость транскрипторов к одному и тому же произведению, наше понимание оригинального текста принципиально не может быть завершено: мысль творца-транскриптора постоянно движется по кругу, расширяющему свои границы, и этот процесс может быть бесконечен. 


\section{Авторлардың үлесі}

Г. Б. Әбдірахман - зерттеу бағыттары мен мәселелерін әзірлеу, ғылыми әдебиеттерді таңдау, мәтінді сыни талдау және нақтылау, қорытындыны тұжырымдау.

А. С. Бекенова - зерттеу жүргізу әдістерін әзірлеу, ғылыми әдебиеттерді талдау, дереккөздермен жұмыс істеу, мәтіннің зерттеу бөлігін дайындау және пысықтау, жобаны орындаушы.

\section{Вклад авторов}

Г. Б. Абдирахман - разработка направления и проблем исследования, подбор научной литературы, критический анализ и доработка текста, концептуализация выводов.

А. С. Бекенова - разработка методологии проведения исследования, анализ научной литературы, работа с источниками, подготовка и доработка исследовательской части текста, исполнитель проекта.

\section{Contribution of authors}

G. B. Abdirakhman - development of research directions and problems, selection of scientific literature, critical analysis and revision of the text, conceptualization of conclusions.

A. S. Bekenova - development of research methodology, analysis of scientific literature, work with sources, preparation and revision of the research part of the text, project executor. 


\section{Список источников}

Bekenova, Aizhan, et al. "Creating Transcriptions and Adaptations for Viola in Kazakhstan: Retrospection, Theory and Practice." Rupkatha Journal on Interdisciplinary Studies in Humanities, vol. 12, no. 6, 2020, pp. 1-14. DOI: 10.21659/rupkatha.v12n6.17.

Galvin, R. White. Viola. Transcriptions: History, Rationale, and Process, with Focus on Selected Works by August Halm. University of California, Santa Barbara, 2014. Howard-Jones, Evlyn. “Arrangements and Transcriptions." Music \& Letters, vol. 16, no. 4, 1935, pp. 305-311. DOI: 10.1093/ml/XVI.4.305.

Lee, Hsiaopei. The History of Viola Transcriptions and a Comprehensive Analysis of the Transcription for Viola and Piano of Beethoven's Violin Sonata. Op. 30, no. 1. 2005. University of Cincinnati. ProQuest Dissertations Publishing, www.proquest.com/ openview/033d731b14c0f5fd1c0619dc09fc9f7c/1?pq-origsite $=$ gscholar\&cbl=187 $50 \&$ diss $=y$. Assessed 10 October 2021.

Vyver, Elmarie. Creating an Idiomatic Transcription for the Viola in Collaboration with the Composer. 2010. The North-West University Potchefstoom campus. Dissertation, www.proquest.com/docview/1504844374. Assessed 10 October 2021.

Башмет, Юрий. Вокзал мечты. Москва, Вагриус, 2007.

Бородин, Борис. Феномен фортепианной транскрипции: опыт комплексного исследования. 2006. Московская государственная консерватория имени П. И. Чайковского, докторская диссертация.

Климова, Вероника. «Транскрипторская деятельность В. В. Борисовского». Молодой ученый, т. 2, № 5 (28), 2011, с. 250-252.

Корноухов, Михаил. "Интерпретация музыкального произведения - от теории к практике». Музыкальное искусство и образование, № 3 (15), 2016, с. 81-96.

Маршанский, Станислав. “Современная отечественная музыка для альта: перспективы изучения". Вестник Челябинского государственного университета. Филология. Искусствоведение, вып. 46, № 22 (203), 2010, с. 164-168.

Михно, Владимир, и Юлия Магомедова. «Переложение виолончельных сюит И. С. Баха для саксофона: методические и исполнительские рекомендации". Вестник музыкальной науки, № 4 (22), 2018, с. 32-42.

Мурзалиева, Саджана. Казахский кобыз в контексте современного функционирования в обществе. 2015. Казахский национальный университет искусств, диссертация магистра искусств.

Погадаева, Наталья. Фёдор Серафимович Дружинин - исполнитель, педагог, композитор. 2009. Выполнена: Оренбургский государственный институт искусств имени Леопольда и Мстислава Ростроповичей. Защищена: Саратовская государственная консерватории имени Л. В. Собинова, кандидатская диссертация. 
Рогаль-Левицкий, Дмитрий. Современный оркестр. Том 1. Москва, Государственное музыкальное издательство, 1953.

Стоклицкая, Евгения. Альтовая педагогика В. В. Борисовского. Москва, Музыка, 2007.

\section{References}

Bashmet, Yurij. Vokzal mechty [Railway Station of Dreams]. Moscow, Vagrius, 2007.

Bekenova, Aizhan, et al. "Creating Transcriptions and Adaptations for Viola in Kazakhstan: Retrospection, Theory and Practice." Rupkatha Journal on Interdisciplinary Studies in Humanities, vol. 12, no. 6, 2020, pp. 1-14. DOI: 10.21659/rupkatha.v12n6.17.

Borodin, Boris. Fenomen fortepiannoy transkriptsii: opyt kompleksnogo issledovani исследования [The Piano Transcription Phenomenon: a Comprehensive Research Experience]. 2006. Tchaikovsky Moscow State Conservatory, doctoral dissertation. (In Russian)

Galvin, R. White. Viola. Transcriptions: History, Rationale, and Process, with Focus on Selected Works by August Halm. University of California, Santa Barbara, 2014.

Howard-Jones, Evlyn. “Arrangements and Transcriptions." Music \& Letters, vol. 16, no. 4, 1935, pp. 305-311. DOI: 10.1093/ml/XVI.4.305.

Klimova, Veronika. “Transkriptorskaya deyatel'nost' V. V. Borisovskogo.” [“Transcript Activity of V. V. Borisovsky"] Young scientist, vol. 2, no. 5 (28), 2011, pp. 252-254. (In Russian)

Kornoukhov, Mihail. "Interpretaciya muzykal'nogo proizvedeniya - ot teorii k praktike." ["Interpretation of a Piece of Music - from Theory to Practice."] Musical Art and Education, no. 3 (15), 2016, pp. 81-96. (In Russian)

Lee, Hsiaopei. The History of Viola Transcriptions and a Comprehensive Analysis of the Transcription for Viola and Piano of Beethoven's Violin Sonata. Op. 30, no. 1. 2005. University of Cincinnati. ProQuest Dissertations Publishing, www.proquest.com/ openview/033d731b14c0f5fd1c0619dc09fc9f7c/1?pq-origsite=gscholar\&cbl=187 50\&diss $=y$. Assessed 10 October 2021.

Marshansky, Stanislav. “Sovremennaya otechestvennaya muzyka dlya al'ta: perspektivy izucheniya." ["Contemporary Russian Music for Viola: Perspectives of Study."] Bulletin of the Chelyabinsk State University. Philology. Art criticism, iss. 46, no. 22 (203), pp. 164-168. (In Russian) 
Mikhno, Vladimir, and Yuliya Magomedova. "Perelozhenie violonchel'nyh syuit I. S. Baha dlya saksofona: metodicheskie i ispolnitel'skie rekomendacii." ["Arrangements of J. S. Bach's Cello Sonatas for Saxophone: Methodological and Performing Recommendations."] Bulletin of Musical Science, no. 4 (22), 2018, pp. 32-42. (In Russian)

Murzaliyeva, Sadzhana. Kazahskij kobyz v kontekste sovremennogo funkcionirovaniya $v$ obshchestve [Kazakh Kobyz in the Context of Modern Functioning in Society]. 2015. Master of Arts thesis. (In Russian)

Pogadaeva, Natal'ya. Fyodor Serafimovich Druzhinin - ispolnitel', pedagog, kompozitor [Fedor Serafimovich Druzhinin - Performer, Teacher, Composer]. 2009. Completed: Leopold and Mstislav Rostropovich Orenburg State Institute of Arts. Defended:

L. V. Sobinov Saratov State Conservatory. PhD thesis. (In Russian)

Rogal-Levitsky, Dmitrij. Sovremennyj orkestr [Modern Orchestra]. Vol. 1. Moscow, State Music Publishing House, 1953. (In Russian)

Stoklitskaya, Evgeniya. Al'tovaya pedagogika V. V. Borisovskogo [Altova Pedagogy of V. Borisovsky]. Moscow, Music, 2007. (In Russian)

Vyver, Elmarie. Creating an Idiomatic Transcription for the Viola in Collaboration with the Composer. 2010. The North-West University Potchefstoom campus.

Dissertation, www.proquest.com/docview/1504844374. Assessed 10 October 2021. 


\section{Гүлнар Әбдірахман, Айжан Бекенова}

Құрманғазы атындағы Қазақ ұлттық консерваториясы (Алматы, Қазақстан)

\section{АЛЬТ ТРАНСКРИПЦИЯЛАРЫН ШЫҒАРУ ҮРДІСІ: ТЕОРИЯДАН ТӘЖІРИБЕГЕ ДЕЙІН}

Аңдатпа. Мақала альтқа арналған транскрипция құру процесінің негізгі кезеңдерін анықтауға арналған. Тақырыптың өзектілігі альт орындаушыларын да, мұғалімдерді де транскрипциялау практикасымен қамтитын альтқа арналған концерттік-педагогикалық репертуарды толықтыру қажеттілігімен анықталады. Қазіргі уақытта бұл үрдіс ерекшеліктері мен оларға тән заңдылықтарды танытатын еңбектер іс жүзінде жоқ.

Зерттеу әдістемесі жалпы ғылыми әдістерге негізделген - талдау, синтездеу, сонымен қатар «транскрипция - бұл көркемдік құндылықтардың бекітілген түсіндірмесі» сияқты Борис Бородиннің әдіснама жолдарынан туындайды. Транскрипция шығару процесінің өзі шығарманың орындаушылық көрінісін оның мәтіндік формасына аудару актісі ретінде ұсынылған.

Зерттеу нәтижелері бойынша транскрипция құрудың негізгі кезеңдері қарастырылды, олардың ішкі мазмұны жасаушының түрімен және оның сыртқы мотивациясымен анықталады. Шығарманы таңдаудың бірінші кезеңі автордың сыртқы ұмтылыстарын жүзеге асырады, оны жұмыстың жаңа нұсқасын жасауға жетелейді және түпнұсқа мәтінімен жұмыс істеу принциптерін анықтайды. Транскрипциялау процесінің негізгі кезеңінің мәні автордың қандай мақсатқа ұмтылатындығына байланысты байқалады, ал мақсат бастапқы көздермен жұмыс істеу әдісін таңдауды анықтайды. Транскрипция жұмысының негізгі кезеңі транскрипциямен тікелей жұмыс істеу тәжірибесіне бағытталған. Жұмыс кезеңінің мақсаты транскрипцияны графикалық түрде бекіту. “Тіркелген интерпретация" жағдайында транскрипция шығару процесі музыкалық мәтіннің әр элементін орындау интерпретациясының мүмкін нұсқаларын аспапта дыбыстаумен қатар жүреді. Үшінші кезең - транскрипцияны сынау кезеңі оны толық орындау түрінде жүзеге асады. Бұл орындау ыңғайлылығын, дыбыс сенімділігі мен түзетулер енгізу қажеттілігін тексеруге мүмкіндік береді.

Мақалада бұрын жасалған үлгілерді қайта өңдеу негізінде транскрипция авторларына альтқа бейімделген музыкалық туындыларды жасауға бағытталған нақты практикалық ұсыныстар берілген.

Тірек сөздер: альт, репертуар, транскрипция, өңдеу, интерпретация, туынды жанрлар, уртекст.

Авторлар мүдделер қақтығысының жоқтығын мәлімдейді. Барлық авторлар қолжазбаның соңғы нұсқасын оқып, мақұлдады.

Дәйексөз үшін: Әбдірахман, Гүлнар, және Айжан Бекенова. «Альт транскрипцияларын шығару үрдісі: теориядан тәжірибеге дейін». Central Asian Journal of Art Studies, т. 6, № 4, 2021 , 55-69 б. DOI: 10.47940/cajas.v6i4.488. 


\section{Gulnar Abdirakhman, Aizhan Bekenova}

Kurmangazy Kazakh National Conservatory

(Almaty, Kazakhstan)

\section{THE PROCESS OF CREATION OF ALTO TRANSCRIPTIONS: FROM THEORY TO PRACTICE}

Abstract. The article is devoted to defining the main stages of process of creating transcriptions for alto. Relevance of the topic is determined by the need to replenish a concert and pedagogical repertoire for the alto, which led to the demand for practice of transcription by both alto performers and teachers. At the moment there are practically no works that reveal the specifics of this process and their inherent regularities.

The research methodology is based on general scientific methods - analysis, synthesis, and also proceeds from the methodological setting of Boris Borodin due to which transcription acts as "a fixed interpretation of artistic values". The very process of creating a transcription is presented as the act of transforming the performing vision of a work into its textual form.

Based on the results of the study, the main stages of creating transcriptions were identified, the internal content of which is determined by the type of a creator and his external motivation. The first, stage of the work selection, implements the external aspirations of the author, which prompted him to turn to the creation of a new version of the work, and determines the principles of working with the original text. The essence of the main stage of the transcription process depends on what goal the author pursues: the goal determines the choice of a method of working with the original source. The main stage of work on transcription has a practice-oriented nature, its purpose is the graphic fixation of the new version of the work. The process of creating a transcription under the conditions of "fixed interpretation" is accompanied by scoring on the instrument possible versions of performing interpretation of each element of a musical text. The third stage is approbation of the transcription, its performance in its entirety. It allows to check convenience of performance, persuasiveness of the sound and need to make adjustments.

The article contains specific practical recommendations for the authors of transcriptions aimed at creating musical works adapted for the alto based on the processing of previously created samples.

Keywords: viola, repertoire, transcription, treatment, interpretation, derived genres, urtext.

Authors declare that there is no conflict of interests. All authors have read and approved the final version of the manuscript.

Cite: Abdirakhman, Gulnar, and Aizhan Bekenova. "The Process of Creation of Alto Transcriptions: from Theory to Practice." Central Asian Journal of Art Studies, vol. 6, no. 4, 2021, pp. 55-69. DOI: 10.47940/cajas.v6i4.488. 


\section{Авторлар туралы мәлімет:}

Гүлнар Бақытқызы

Әбдірахман - өнертану

кандидаты, Құрманғазы

атындағы Қазақ Ұлттық

консерваториясының

музыкатану және композиция

кафедрасының профессоры

(Алматы, Қазақстан)
Сведения об авторах:

\section{Гульнар Бахыткызы}

Абдирахман - кандидат

искусствоведения, профессор

кафедры музыковедения

и композиции Қазахской

национальной консерватории

имени Курмангазы (Алматы,

Қазахстан)

ORCID ID: 0000-0001-9803-0969

email: gulnarabd@mail.ru

\section{Authors' bio:}

\section{Gulnar B. Abdirakhman -}

Candidate of Art History, Professor, Department of Musicology and Composition, Kurmangazy Kazakh National

Conservatory (Almaty, Kazakhstan)

\section{Айжан Слямқызы Бекенова - Құрманғазы атындағы Қазақ Ұлттық консерваториясының ішекті аспаптар кафедрасының доценті (Алматы, Қазақстан)}

\author{
Айжан Слямовна Бекенова - \\ доцент кафедры струнных \\ инструментов Қазахской \\ национальной консерватории \\ имени Курмангазы (Алматы, \\ Қазахстан)
}

